\title{
The Effect of Group Exercise Program on Cognitive Function of Elderly people
}

\begin{abstract}
The goal of this study was to assess the effect of a group exercise program on cognitive function of elderly people. Subjects were chosen to be elders with dementia having minor to moderate degrees of cognitive function. Study was started out by randomly dividing the 16 subjects into two groups, each with 8 people; the group exercise group and the control group. The group exercise group performed 8 weeks of group exercise program and general physiotherapy while the control group only performed general physiotherapy. Cognitive function was measured by Korean version mini-mental state examination. The study group's attention and calculation statistically significantly improved but the control group saw no statistically significant change. The group exercise program affected improvement in cognitive function of elderly people with dementia and in particular, was effective for enhancing their attention and calculation.
\end{abstract}

Key words: Group Exercise; Cognitive Function; Attention; Calculation; Older

\author{
Nyeon Jun Kima, Moo Ki Kima, Ok \\ Kon Moon ${ }^{b}$, Ho Jung $\mathrm{An}^{\mathrm{c}}$, Hee \\ Joon Shin', Yoo Rim Choie, Jung \\ San Wang', Joon Hee Lee $^{9}$, Joo \\ Hyun Park', Soon Hee Kim' \\ aPohang College, Pohang; 'Howon University, \\ Gunsan; 'Dongnam Health College, Suwon; \\ "Kyungwoon University, Gumi; ${ }^{\mathrm{e} T}$ Taegu Science \\ University, Daegu; 'Yeoju Institute of Technology, \\ Yeoju; ' ${ }^{9}$ Cheongju University, Cheongju; " $S$ Suwon \\ Women's College, Suwon; 'Yongin University, \\ Yongin, Korea \\ Received : 15 May 2014 \\ Revised : 17 July 2014 \\ Accepted : 15 September 2014 \\ Address for correspondence \\ Soon Hee Kim, PT, Ph.D \\ Department of Physical Therapy, Yongin \\ University, 470 Samga-dong, Cheoingu, \\ Yongin, Korea \\ Tel: 82-31-8020-2774 \\ E-mail: shkim@yongin.ac.kr
}

\section{INTRODUCTION}

The rate of Korea's elderly population aged 65 or older was $7.2 \%$ in 2000 . As the society entered into an aging society, the population of elderly people was $5,016,000$ in 2008, accounting for $103, \%$, and the society will be a aged society with the elderly people making up $14.3 \%$ in 2018, and be a super-aged society with the elderly people accounting for 20.8\%(1). Among them, the prevalence for dementia of elderly people aged 65 or older was reported to be 6.8 to $12.8 \%(2)$. As of 2007 , the number of elderly people with dementia in Korea was 3,909,000 (8.3\%) among $4,810,000$ and is expected to increase to $580,000(3)$ and therefore the resulting social burden will grow. Dementia refers to a progressive organic mental disorder and is characterized by chronic personality collapse, confusion, orientation loss, stupor, loss of intellectual capacity and function, memory disorder, judgment disorder, and impulse(4). The number of causative diseases for dementia is about 50 kinds including degenerative diseases, cardiovascular diseases, and metabolic diseases. Those with dementia resulting from diverse causes have different clinical progression. According to their clinical progression, dementia is classified into progressive, degenerative, irreversible, and curable dementia(5). What is representative among the causes of dementia is vascular dementia and Alzheimer's disease.

Treatment of dementia requires both drug and non-drug therapy. Among them, non-drug therapies for dementia include group exercise therapy, group art therapy, group music therapy, group reminiscence therapy, reality therapy, behavioral therapy, light therapy, walking, pet therapy, attention training program, and functional technical training. In addition, home exercise programs or rehabilitation programs after hospitalization for elderly people with 
dementia are conducted in diverse ways(6). A lot of domestic research related to cognitive function among non-drug therapies for elderly people with dementia has been reported such as group reminiscence therapy(7), a recreation program(8), group art therapy(9), and an exercise program(10), but the number of studies of group exercise programs is very small. Accordingly, this study aims to examine the effects of a group exercise program on cognitive function of elderly people with mild to moderate dementia.

Table 1. General characteristics of the subjects

\begin{tabular}{ccccc}
\hline & ${ }^{\mathrm{a}} \mathrm{GEG}(\mathrm{n}=8)$ & ${ }^{\mathrm{b}} \mathrm{CG}(\mathrm{n}=8)$ & Total & $\mathrm{p}$ \\
\hline Gender(mal/female) & $1 / 7$ & $1 / 7$ & $2 / 14$ & \\
Age(yr) & $72.75 \pm 6.15^{\circ}$ & $72.12 \pm 2.53$ & $72.43 \pm 4.56$ & .958 \\
Hight(cm) & $161.50 \pm 7.46$ & $158.12 \pm 6.97$ & $159.81 \pm 7.19$ & .344 \\
Weight(kg) & $56.75 \pm 7.42$ & $51.87 \pm 5.56$ & $54.31 \pm 6.81$ & .168 \\
K-MMSE(total score) & $16.50 \pm 1.19$ & $17.13 \pm 1.95$ & $16.81 \pm 1.60$ & .590 \\
\hline
\end{tabular}

${ }^{a}$ GEG : Group exercise group

${ }^{\mathrm{b}} \mathrm{CG}$ : Control group

${ }^{\mathrm{M}} \pm \mathrm{SD}$ : Mean \pm standard deviation

\section{Procedure}

The exercise group performed 8 weeks of group exercise program and general physical therapy, while the control group only performed general physical therapy. Cognitive function of the exercise group and the control group was measured before the study and 8 weeks after the study. Group exercise program involved in the period of 8weeks for around 35 minutes a day, three times per week.

\section{Measurement scale}

Cognitive function were tested using the Korean version of mini mental state exam(K-MMSE). The $\mathrm{K}$-MMSE was made from the mini-mental state exam(MMSE) developed by Folstein et al. with revisions and supplementation by Park and Gwon. It is set to have a full score of 30 points for 12 questions in areas as follows; orientation, registration, recall, attention and calculation, language and visuospa$\operatorname{tial}(11,12)$.

\section{Data analysis}

In the present study, the statistical program SPSS

\section{METHODS}

\section{Subject}

Subjects of this research were selected from the patients of $\mathrm{OO}$ hospital in Yong In, Gyeonggi-do. Subjects were chosen to be elders with dementia having minor to moderate degrees of cognitive function. Study was started out by randomly dividing the 16 subjects into two groups, each with 8 people; group exercise group and the control group. General characteristics of the subjects are as follows(Table 1).
18.0 was used for data analysis. General characteristics of the study subjects were produced as frequency analysis, means and standard deviations. Wilcoxon signed-ranks tests were conducted to examine changes in the elderly persons' cognitive function between before and after the exercises and MannWhitney tests were conducted to examine differences in changes between the groups. To test statistical significance, the significance level was set to $a=.05$.

\section{RESULTS}

In the study group, attention and calculation statistically significantly improved while orientation, registration, recall, language and visualspatial, and total score did not statistically significantly differ after the exercise. In the control group, there were no statistically significant differences in all items after the intervention.

According to the result of comparing the study group and the control group, cognitive function scores increased in the control group compared to the group exercise group with no statistically significant differences(p<.05)(Table 4). 
Table 2. Difference of cognitive function changes by exercise

\begin{tabular}{|c|c|c|c|c|c|c|c|}
\hline MMSE-K & group & pre test(mean $\pm S D)$ & post test(mean $\pm S D)$ & Z & $p$ & Z & $p$ \\
\hline \multirow{2}{*}{ Orientation } & GEG & $3.88 \pm .64$ & $3.88 \pm .83$ & .000 & 1.000 & \multirow{2}{*}{-.464} & \multirow{2}{*}{.643} \\
\hline & CG & $4.13 \pm .835$ & $4.38 \pm .744$ & -.577 & .564 & & \\
\hline \multirow{2}{*}{ Registration } & SEG & $2.38 \pm .51$ & $2.38 \pm 1.06$ & .000 & 1.000 & \multirow{2}{*}{-.387} & \multirow{2}{*}{.690} \\
\hline & CG & $2.25 \pm .707$ & $2.00 \pm 1.069$ & -.707 & .480 & & \\
\hline \multirow{2}{*}{ Attention and calculation } & SEG & $1.50 \pm .75$ & $2.38 \pm .74$ & -2.070 & $.038^{*}$ & \multirow{2}{*}{-1.896} & \multirow[b]{2}{*}{.058} \\
\hline & CG & $1.75 \pm .886$ & $1.63 \pm .916$ & -.378 & .705 & & \\
\hline \multirow{2}{*}{ Recall } & SEG & $1.63 \pm .51$ & $1.88 \pm .99$ & -1.000 & .317 & \multirow{2}{*}{-1.113} & \multirow{2}{*}{.266} \\
\hline & $C G$ & $1.38 \pm .916$ & $1.25 \pm 1.035$ & -.577 & .564 & & \\
\hline \multirow{2}{*}{ Language and visuospatial } & $\mathrm{SEG}$ & $7.13 \pm .64$ & $7.13 \pm 1.35$ & .000 & 1.000 & \multirow{2}{*}{-.335} & \multirow{2}{*}{.738} \\
\hline & CG & $7.63 \pm .744$ & $7.50 \pm 1.414$ & -.378 & .705 & & \\
\hline \multirow{2}{*}{ Total } & SEG & $16.50 \pm 1.19$ & $17.63 \pm 1.76$ & -1.581 & .114 & \multirow{2}{*}{-1.232} & \multirow{2}{*}{.218} \\
\hline & $C G$ & $17.13 \pm 1.959$ & $16.75 \pm 1.982$ & -.552 & .581 & & \\
\hline
\end{tabular}

\section{DISCUSSION}

As the average lifespan of humans goes up, the elderly population and those with dementia have increased(3). The symptoms of dementia include behavioral psychological disorders, depression, delusion, hallucination, and behavioral disorders, cognitive function disorders, and disorders in activities of daily living (13). This study applied a group exercise program to elderly people with mild-to-moderate dementia and studied the effects of the program on their cognitive function. According to the result, the group exercise group's cognitive function who participated in a group exercise program improved and such changes were statistically significant in particular, in attention and calculation. Meanwhile, cognitive function of a control group which did not take part in a group exercise program did not statistically significantly change. In comparison of cognitive function between the group exercise group and the control group, the group exercise group's cognitive function improved but the control group's cognitive function decreased, with no statistical differences. Given such results, it can be estimated that a group exercise program positively affects cognitive function of elderly people with dementia.

Volgel et al. noted that long-term exercise prevented elderly people's impairment of cognitive function or decreased the occurrence of dementia(14). Lytle et al. reported that exercises played an important part in preventing cognitive ability of elderly people with dementia(15). Yaguez et al. observed that exercise therapies were effective for enhancing attention, visual memory, and working memory of elderly people with dementia(16). Kim et al. asserted that regular exercises and physical activities played a crucial role in maintaining elderly people's mental and physical health and were effective for preventing their dementia and training their cognitive function(17). Brinton reported that regular aerobic exercises of moderate intensity provided a lot of oxygens to the brain, greatly contributing to improvement in cognitive function of female dementia patients(18). Um et al. reported that regular exercise improved cognitive function of elderly people with dementia(19). Wang reported that application of a hand motion exercise program ameliorated cognitive function of elderly people with dementia(6). The above research results are consistent with the present study result in that exercise positively affected elderly people with dementia. However, the present study result is not consistent with a study result by Son who applied an exercise program to elderly people with dementia and reported there were no significant changes in their cognitive function after the intervention(20). 


\section{CONCLUSIONS}

In order to examine the effects of group exercise on cognitive function of elderly people, a group exercise program was conducted for eight weeks. The group exercise program was helpful to enhancing their attention and calculation. A group exercise for elderly people with dementia is considered to have positive influence on their cognitive function.

\section{REFERENCES}

1. Ministry of Health and Welfare. In 2008, the National Health Expenditures and the National Health Accounts. Ministry of Health and Welfare; 2009.

2. Seo GH, Kim JG, Yeon BG, Park SG, Yu GY, Yang BG, Kim YS, Cho MJ. Prevalence and risk factors of dementia and depression in the elderly . Journal of the korean neuropsychiatric association. 2000; 39(5), 809-824.

3. Ministry of Health and Welfare. In 2007, the National Health Expenditures and the National Health Accounts. Ministry of Health and Welfare; 2008 .

4. Mosby' s medical. Nursing \& Allied Health Dictionary. Mosby 6th ED; 2002.

5. Korean Dementia association. Dementia : a clinical approach. Academia; 2006.

6. Wang JS. The effects of hand movement exercise program on the improvement of recognition ability in the dementia old adults. Masters Thesis; 2004.

7. Tsuda R. Measuring the effectiveness of the recollection method for senior citizens with dementia: behavior observation scale. Japanese journal of behavior therapy 2011; 37(2): 77-90.

8. Yang HG. The effects of recreational music therapy on the cognitive function of the aged with dementia. Journal of korea artstherapy institute 2007; 7(1): 28-49.

9. Reid S, Hartzell E. Art therapy with a group of dementia caregivers: exploring wellbeing through social support and creative expression. Alzhemiers and dementia 2013; 9(4): 485.

10. Hogan DB, Bailey P, Black S, Carswell A, Chertkow H, Clarke B, Cohen C, Fisk JD, Forbes D, Man-Son-Hing M, Lanctôt K, Morgan D, Thorpe L. Diagnosis and treatment of dementia: 5. nonpharmacologic and pharmacologic therapy for mild to moderate dementia. CAMJ 2008; 179(10): $1019-1026$.

11. Park JH, Kwon YC. Standardization of korean version of the mini-mental state examination for use in the elderly 1989; 28(1): 125-135.

12. Park TJ. Cognitive neural mechanisms of aging. Journal of korean psychology association 2004; 16(3): 317-336.

13. Lobo A, Saz P, Marcos G. The prevalence of dementia and depression in the elderly community in a southern european population. Arch gen psychiatry 1995; 52, 497-506.

14. Vogel T, Brechat PH, Leprêtre PM, Kaltenbach G, Berthel M, Lonsdorfer J. Health benefits of physical activity in older patients: a review. Int $\mathrm{j}$ clin pract 2009; 63(2): 303-20.

15. Lytle ME, Vander BJ, Pandav RS, Dodge, HH, Ganguli M. Exercise level and cognitive decline: The movies project. Alzheimer dis assoc disord 2004; 18: 57-64.

16. Yágüez L, Shaw KN, Morris R, Matthews D. The effects on cognitive functions of a movementbased intervention in patients with alzheimer's type dementia: a pilot study. Int j geriatr psychiatry 2011; 26(2): 173-81.

17. Kim DY, Kim IS, Kim TY, Park RJ, Park JM, Son GC, Lee GN, Lee EA, Jung HG, Han GI. Dementia Prevention and Cognitive Rehabilitation Program. Suhyeonsa; 2004.

18. Brinton R. A women's health issue: alzheimer's disease and strategies for maintaining cognitive health. Int j fertil womens med 1999; 44; 174-185.

19. Um SY, Kwak YS. The effects of regular exercise on cognitive function and blood lipid in woman patient with senile dementia. Korean journal of sport science 2004; 15(1): 57-65.

20. Son HH. The effects of exercise program on activities of daily living and balance in elderly with dementia. University of Daegu. Masters Thesis; 2007. 